

CrossMark \&lick for updates

Cite this: Polym. Chem., 2016, 7, 3864

Received 20th April 2016, Accepted 11th May 2016

DOI: 10.1039/c6py00696e

www.rsc.org/polymers

\title{
Bespoke cationic nano-objects via RAFT aqueous dispersion polymerisation $\uparrow$
}

\author{
M. Williams, ${ }^{* a}$ N. J. W. Penfold, ${ }^{a}$ J. R. Lovett, ${ }^{a}$ N. J. Warren, ${ }^{a}$ C. W. I. Douglas, ${ }^{b}$ \\ N. Doroshenko, ${ }^{b}$ P. Verstraete, ${ }^{c}$ J. Smets ${ }^{c}$ and S. P. Armes ${ }^{\star a}$
}

\begin{abstract}
A range of cationic diblock copolymer nanoparticles are synthesised via polymerisation-induced selfassembly (PISA) using a RAFT aqueous dispersion polymerisation formulation. The cationic character of these nanoparticles can be systematically varied by utilising a binary mixture of two macro-CTAs, namely non-ionic poly(glycerol monomethacrylate) (PGMA) and cationic poly[2-(methacryloyloxy)ethyl]trimethylammonium chloride (PQDMA), with poly(2-hydroxypropyl methacrylate) (PHPMA) being selected as the hydrophobic core-forming block. Thus a series of cationic diblock copolymer nano-objects with the general formula $\left([1-n] \mathrm{PGMA}_{x}+[n] \mathrm{PQDMA} A_{y}\right)-\mathrm{PHPMA}_{z}$ were prepared at $20 \% \mathrm{w} / \mathrm{w}$ solids, where $n$ is the mol fraction of the cationic block and $x, y$ and $z$ are the mean degrees of polymerisation of the non-ionic, cationic and hydrophobic blocks, respectively. These cationic diblock copolymer nanoparticles were analysed in terms of their chemical composition, particle size, morphology and cationic character using ${ }^{1} H$ NMR spectroscopy, dynamic light scattering (DLS), transmission electron microscopy (TEM), and aqueous electrophoresis, respectively. Systematic variation of the above PISA formulation enabled the formation of spheres, worms or vesicles that remain cationic over a wide $\mathrm{pH}$ range. However, increasing the cationic character favors the formation of kinetically-trapped spheres, since it leads to more effective steric stabilisation which prevents sphere-sphere fusion. Furthermore, cationic worms form a soft freestanding gel at $25^{\circ} \mathrm{C}$ that undergoes reversible degelation on cooling, as indicated by variable temperature oscillatory rheology studies. Finally, the antimicrobial activity of this thermo-responsive cationic worm gel towards the well-known pathogen Staphylococcus aureus is examined via direct contact assays.
\end{abstract}

\section{Introduction}

It has been widely reported that the self-assembly of block copolymers can produce spherical micelles, ${ }^{1}$ worm-like micelles ${ }^{2,3}$ rod-like micelles, ${ }^{4-6}$ vesicles, ${ }^{1,7-10}$ nanotubes ${ }^{11,12}$ and toroids. ${ }^{13}$ Traditionally, block copolymer self-assembly involves a post-polymerisation processing step that is typically conducted in dilute solution. ${ }^{1,14-16}$ However, recent advances in polymerisation-induced self-assembly (PISA) via

\footnotetext{
${ }^{a}$ Department of Chemistry, University of Sheffield, Brook Hill, Sheffield, South Yorkshire S3 7HF, UK. E-mail: m.s.williams@sheffield.ac.uk, s.p.armes@sheffield.ac.uk

${ }^{b}$ School of Clinical Dentistry, University of Sheffield, Claremont Crescent, Sheffield S10 2TA, UK

${ }^{c}$ Procter \& Gamble, Temselaan 100, 1853 Strombeek Bever, Belgium

$\dagger$ Electronic supplementary information (ESI) available: Aqueous gel permeation chromatograms of PQDMA macro-CTAs, TEM images of PQDMA-PHPMA spheres, DMF gel permeation chromatograms of PGMA-PHPMA di-block copolymers, TEM images of cationic worms, critical gelation concentration determination of cationic worms and rheology studies of cationic and non-ionic worms. See DOI: 10.1039/c6py00696e
}

reversible addition-fragmentation chain transfer (RAFT) polymerisation ${ }^{17-19}$ has enabled diblock copolymers to be prepared in the form of sterically-stabilised nanoparticles at relatively high solids (25-50\%), ensuring much lower solution viscosities compared to conventional solution polymerisations. The broad applicability of this PISA approach is now widely recognised, with successful formulations being reported in aqueous solution (via either dispersion ${ }^{20-23}$ or emulsion ${ }^{24-28}$ polymerisation), as well as polar solvents such as lower alcohols ${ }^{29-31}$ and non-polar solvents like $n$-alkanes. ${ }^{32}$ Furthermore, controlled/living radical polymerisation techniques enable efficient polymerisations ( $\sim 99 \%$ conversion within $2 \mathrm{~h})$ and relatively narrow molecular weight distributions $\left(M_{\mathrm{w}} / M_{\mathrm{n}}<\right.$ 1.30). ${ }^{33}$ In a typical aqueous PISA formulation, the watersoluble steric stabiliser block is prepared first, with the subsequent growth of the water-insoluble block driving in situ phase separation. The final copolymer morphology in such aqueous PISA-based systems is dictated by (i) the copolymer concentration, (ii) the targeted $\mathrm{AB}$ diblock copolymer composition and (iii) the mean degree of polymerisation of the stabiliser block. ${ }^{34,35}$ RAFT polymerisation of 2-hydroxypropyl 
methacrylate (HPMA) using a poly(glycerol monomethacrylate)-based macromolecular chain transfer agent (PGMA macro-CTA) using a RAFT aqueous dispersion polymerisation protocol has been intensively investigated by our group. ${ }^{22,23,35-38}$ This prototypical aqueous PISA formulation allows the efficient formation of $\mathrm{AB}$ block copolymer nanoparticles with precise control over particle size and morphology by fixing the degree of polymerisation of the PGMA stabiliser block while systematically varying the degree of polymerisation of the core-forming PHPMA block. The construction of detailed phase diagrams has enabled pure spheres, worms, or vesicles to be reproducibly targeted..$^{23}$ Furthermore, PGMA-PHPMA worms form free-standing soft hydrogels at $25{ }^{\circ} \mathrm{C}$ due to multiple inter-worm contacts, with reversible degelation occurring on cooling to $4{ }^{\circ} \mathrm{C}$ as a result of a wormto-sphere order-order transition. ${ }^{35,36,38}$ Such thermo-responsive worm gels are readily sterilisable via cold ultrafiltration and have potential biomedical applications for the long-term storage and preservation of human stem cells ${ }^{39}$ or red blood cells. $^{40}$

In principle, the nanoparticle surface chemistry can be fine-tuned by varying the stabiliser block used in such PISA formulations. One approach is to use a polyelectrolyte as a stabiliser block to produce highly charged nanoparticles. However, this typically leads to just spherical morphologies being obtained, because the strong electrostatic repulsion between the adjacent cationic or anionic chains within the steric stabiliser layer prevents the efficient sphere-sphere fusion required to form higher order morphologies such as worms or vesicles. ${ }^{24,27,41,42}$

It has been widely reported that colloidally stable cationic nanoparticles can possess anti-microbial properties. ${ }^{43-46}$ Previously, we have utilised a cationic polyelectrolytic block based on quaternised poly[2-(methacryloyloxy)ethyl] trimethylammonium chloride (PQDMA) to polymerise HPMA in order to form sterically-stabilised nanoparticles via PISA. ${ }^{42}$ In the absence of salt, block copolymer self-assembly was somewhat problematic due to the strong repulsion between the neighbouring cationic PQDMA stabiliser chains. However, in the presence of salt the unfavourable electrostatics could be overcome by reducing the charge density within the coronal stabiliser layer by either (i) statistically copolymerising QDMA monomer with a non-ionic GMA comonomer or (ii) using a binary mixture of a PQDMA macro-CTA and a PGMA macro-CTA. In practice, the latter approach proved to be particularly useful in allowing access to worm and vesicle copolymer morphologies. ${ }^{42}$

In the present work, this binary macro-CTA approach is revisited. In particular, the effect of varying the relative degrees of polymerisation of the PQDMA and PGMA stabiliser blocks on the nanoparticle surface charge is investigated (see Fig. 1). A detailed phase diagram is constructed to examine how the degree of polymerisation of the core-forming PHPMA block and the proportion of cationic stabiliser block affects the formation of cationic spheres, worms and vesicles. Finally, a preliminary investigation of the anti-microbial properties of a cationic thermo-responsive worm gel against a strain of the well-known pathogen Staphylococcus aureus is reported.

\section{Experimental section}

\section{Materials}

Glycerol monomethacrylate (GMA) was donated by GEO Specialty Chemicals (Hythe, UK) and used without further purification. 4-Cyano-4-(2-phenylethanesulfanylthiocarbonyl) sulfanylpentanoic acid (PETTC) RAFT agent and its methylated analogue were synthesised as previously reported..$^{31,47}$ [2-(Methacryloyloxy)ethyl]trimethylammonium chloride solution (QDMA; 80\% w/w in $\mathrm{H}_{2} \mathrm{O}$ ), 2-hydroxypropyl methacrylate (HPMA; 97\%), 4,4'-azobis(4-cyanopentanoic acid) (ACVA; 99\%), ethanol, methanol, dichloromethane and deuterium oxide $\left(\mathrm{D}_{2} \mathrm{O}\right)$ were purchased from Sigma-Aldrich (UK) and were used as received. Acetonitrile and dimethyl formamide were purchased from Fisher scientific (Loughborough, UK). Methanol-
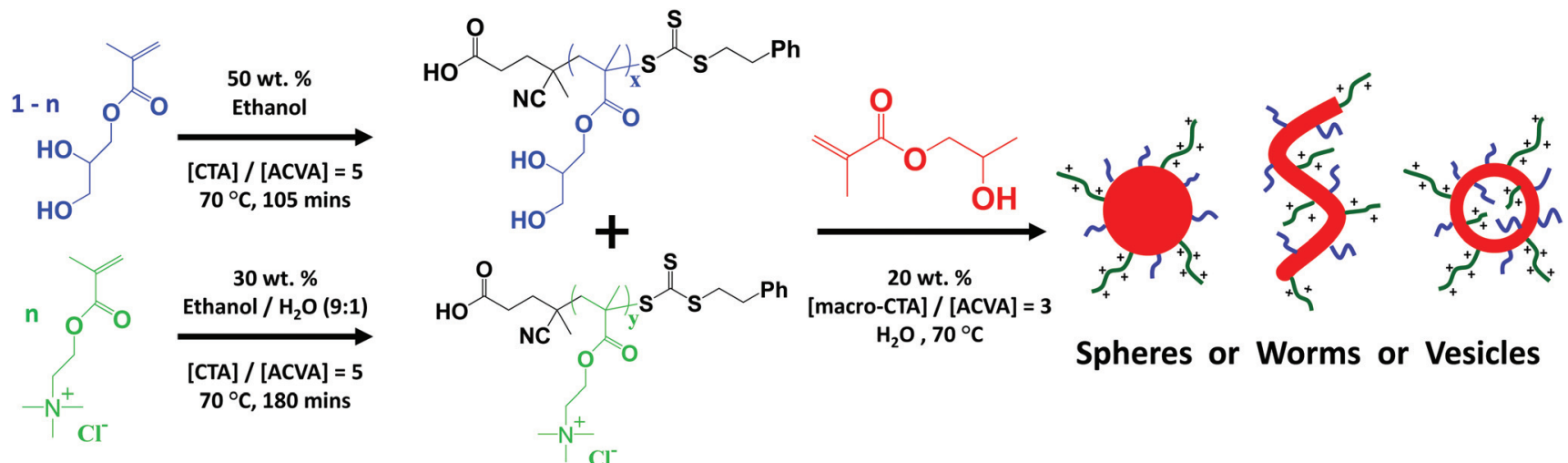

Fig. 1 Synthesis of cationic diblock copolymer nanoparticles with the general formula $\left([1-n]\right.$ PGMA $_{x}+[n]$ PQDMA $\left.y\right)-$ PHPMA $_{z}$ by RAFT aqueous dispersion polymerisation of HPMA using a binary mixture of non-ionic and cationic macro-CTAs. Optimisation of $n, x, y$, and $z$ enable the formation of cationic spheres, worms or vesicles. 
$d_{4}\left(\mathrm{CD}_{3} \mathrm{OD}\right)$ was purchased from Goss Scientific Ltd (Cheshire, UK). Deionised water was used for all experiments.

\section{Synthesis of poly(glycerol monomethacrylate) (PGMA) macro- CTA via RAFT solution polymerisation}

A typical protocol for the synthesis of PGMA 62 was as follows. 4-Cyano-4-(2-phenylethanesulfanylthiocarbonyl)sulfanylpentanoic acid (PETTC) RAFT agent (2.40 mmol, $0.815 \mathrm{~g}$ ), ACVA initiator $(0.50 \mathrm{mmol}, 0.135 \mathrm{~g}$, CTA/ACVA molar ratio $=5.0)$ and GMA monomer (0.156 mol, $25.0 \mathrm{~g})$ were weighed into a $100 \mathrm{~mL}$ round-bottom flask. Ethanol $(25.9 \mathrm{~mL})$ was added to afford a 50\% w/w GMA solution and the resulting solution was purged with nitrogen for $30 \mathrm{~min}$. The sealed flask was immersed into an oil bath set at $70{ }^{\circ} \mathrm{C}$ for $105 \mathrm{~min}$ (final GMA conversion $=84 \%$, as judged by ${ }^{1} \mathrm{H}$ NMR spectroscopy) and the polymerisation was subsequently quenched by immersion in liquid nitrogen. Methanol $(50 \mathrm{~mL})$ was added to the reaction solution, followed by precipitation into a ten-fold excess of dichloromethane $\left(\begin{array}{ll}1 & \mathrm{~L}\end{array}\right)$. The precipitated PGMA macro-CTA was redissolved in methanol and the precipitation was repeated. After dissolution using deionised water, the resulting aqueous polymer solution was freeze-dried overnight. ${ }^{1} \mathrm{H}$ NMR analysis indicated a mean degree of polymerisation of 62 for this PGMA macro-CTA. Its $M_{\mathrm{n}}$ and $M_{\mathrm{w}} / M_{\mathrm{n}}$ were $16500 \mathrm{~g} \mathrm{~mol}^{-1}$ and 1.12, respectively, as judged by DMF GPC using a refractive index detector and a series of near-monodisperse poly(methyl methacrylate) calibration standards.

\section{Synthesis of poly[2-(methacryloyloxy)ethyl] trimethylammonium chloride (PQDMA) macro-CTA via RAFT solution polymerisation}

A typical protocol for the synthesis of PQDMA ${ }_{95}$ was as follows. 4-Cyano-4-(2-phenylethanesulfanylthiocarbonyl)sulfanylpentanoic acid (PETTC) RAFT agent (0.58 mmol, $0.196 \mathrm{~g}$ ), ACVA initiator (0.12 mmol, $0.032 \mathrm{~g}$, CTA/ACVA molar ratio $=5.0)$ and QDMA monomer (0.058 mol, $15.0 \mathrm{~g}, 80 \% \mathrm{w} / \mathrm{w}$ in water) were weighed into a $100 \mathrm{~mL}$ round-bottom flask. Ethanol $(25.6 \mathrm{~mL})$ was added to afford a 30\% w/w QDMA solution in a 9:1 ethanol/water solution and the resulting solution was purged with nitrogen for $30 \mathrm{~min}$. The sealed flask was immersed into an oil bath set at $70{ }^{\circ} \mathrm{C}$ for $180 \mathrm{~min}$ (final QDMA conversion = $79 \%$, as judged by ${ }^{1} \mathrm{H}$ NMR spectroscopy) and the polymerisation was subsequently quenched by immersion in liquid nitrogen. Purification was achieved by precipitation into a tenfold excess of acetonitrile ( $0.5 \mathrm{~L})$. The isolated PQDMA macroCTA was redissolved in deionised water and this precipitation purification protocol was repeated. Following dissolution with deionised water, the aqueous polymer solution was freezedried overnight. ${ }^{1} \mathrm{H}$ NMR analysis indicated a mean degree of polymerisation of 95 for this PQDMA macro-CTA. Aqueous GPC analysis, using a pH 2 aqueous eluent, a refractive index detector, and a series of near-monodisperse poly(ethylene oxide) calibration standards, indicated an $M_{\mathrm{n}}$ and $M_{\mathrm{w}} / M_{\mathrm{n}}$ of $25300 \mathrm{~g} \mathrm{~mol}^{-1}$ and 1.19, respectively. The same protocol was used to synthesise a PQDMA 26 macro-CTA with an $M_{\mathrm{n}}$ and $M_{\mathrm{w}}$ /
$M_{\mathrm{n}}$ of $9500 \mathrm{~g} \mathrm{~mol}^{-1}$ and 1.23 , as well as a PQDMA 48 macro-CTA with an $M_{\mathrm{n}}$ of $15500 \mathrm{~g} \mathrm{~mol}^{-1}$ and an $M_{\mathrm{w}} / M_{\mathrm{n}}$ of 1.23 .

\section{Synthesis of PGMA-PHPMA diblock copolymer nanoparticles by RAFT aqueous dispersion polymerisation}

The typical protocol for the synthesis of $\mathrm{PGMA}_{62}-\mathrm{PHPMA}_{200}$ nanoparticles at $20 \% \mathrm{w} / \mathrm{w}$ solids was as follows. $\mathrm{PGMA}_{62}$ macro-CTA (0.300 g, $0.030 \mathrm{mmol}$ ), ACVA (3.0 mg, $0.01 \mathrm{mmol}$, CTA/ACVA molar ratio $=3.0)$ and HPMA monomer $(0.836 \mathrm{~g}$, $6.00 \mathrm{mmol}$; target $\mathrm{DP}=200$ ) were weighed into a $25 \mathrm{~mL}$ roundbottomed flask. Deionised water $(4.6 \mathrm{~mL})$ was then added to give a $20.0 \% \mathrm{w} / \mathrm{w}$ aqueous solution, which was degassed for $30 \mathrm{~min}$ prior to immersion in an oil bath set at $70^{\circ} \mathrm{C}$. The reaction solution was stirred for $5 \mathrm{~h}$ to ensure complete HPMA monomer conversion (as judged by ${ }^{1} \mathrm{H}$ NMR) and then quenched by cooling and exposure to air.

\section{Synthesis of PQMA-PHPMA diblock copolymer nanoparticles by RAFT aqueous dispersion polymerisation}

The typical protocol for the synthesis of $\mathrm{PQDMA}_{26}-\mathrm{PHPMA}_{200}$ at $10 \% \mathrm{w} / \mathrm{w}$ solids was as follows. PQMA 26 macro-CTA $(0.080 \mathrm{~g}$, $0.014 \mathrm{mmol}$ ), ACVA $(1.30 \mathrm{mg}, 0.005 \mathrm{mmol}$, CTA/ACVA molar ratio $=3.0)$ and HPMA monomer $(0.394 \mathrm{~g}, 2.8 \mathrm{mmol}$; target $\mathrm{DP}=200$ ) were weighed into a $25 \mathrm{~mL}$ round-bottomed flask. Deionised water $(4.3 \mathrm{~mL})$ was then added to give a $10.0 \% \mathrm{w} / \mathrm{w}$ aqueous solution, which was degassed for $30 \mathrm{~min}$ prior to immersion in an oil bath set at $70{ }^{\circ} \mathrm{C}$. The reaction solution was stirred for $5 \mathrm{~h}$ to ensure complete HPMA monomer conversion (as judged by ${ }^{1} \mathrm{H}$ NMR) and then quenched by cooling and exposure to air.

Synthesis of $\left([1-n]\right.$ PGMA $_{x}+[n]$ PQDMA $\left._{y}\right)-$ PHPMA $_{z}$ diblock copolymer nanoparticles by RAFT aqueous dispersion polymerisation using a binary mixture of macro-CTAs

The typical protocol for the synthesis of $\left(0.9 \mathrm{PGMA}_{62}+\right.$ $\left.0.1 \mathrm{PQDMA}_{95}\right)-\mathrm{PHPMA}_{200}$ at $20 \% \mathrm{w} / \mathrm{w}$ solids was as follows. PGMA $_{62}$ macro-CTA $(0.241 \mathrm{~g}, 0.023 \mathrm{mmol})$, PQDMA ${ }_{95}$ macroCTA (0.052 g, $0.003 \mathrm{mmol}$ ), ACVA (2.40 mg, $0.009 \mathrm{mmol}$, CTA/ ACVA molar ratio $=3.0)$ and HPMA monomer $(0.746 \mathrm{~g}$, $5.20 \mathrm{mmol}$; target $\mathrm{DP}=200$ ) were weighed into a $25 \mathrm{~mL}$ roundbottomed flask. Deionised water $(4.2 \mathrm{~mL}$, producing a $20.0 \%$ $\mathrm{w} / \mathrm{w}$ aqueous solution) was then added and the solution was degassed for 30 min prior to immersion in an oil bath set at $70{ }^{\circ} \mathrm{C}$. The reaction solution was stirred for $5 \mathrm{~h}$ to ensure complete HPMA monomer conversion (as judged by ${ }^{1} \mathrm{H}$ NMR), with quenching achieved by cooling and exposure to air.

\section{Evaluation of the antimicrobial activity of a cationic worm gel}

Diblock copolymer nanoparticles with the general formula $\left(0.95 \mathrm{PGMA}_{62}+0.05 \mathrm{PQDMA}_{95}\right)-\mathrm{PHPMA}_{200}$ were synthesised at $20 \% \mathrm{w} / \mathrm{w}$ solids using the above protocol. The resulting cationic worm gel was diluted to $12.5 \% \mathrm{w} / \mathrm{w}$ solids by cooling to $2{ }^{\circ} \mathrm{C}$, followed by addition of the desired volume of deionised water and warming to room temperature. As a control, a nonionic worm gel was also prepared using methylated PETTC as a RAFT CTA, which was synthesised using a previously 
reported protocol. ${ }^{47}$ The effect of each copolymer gel on a clinical isolate of Staphylococcus aureus S235 was assessed using two methods: a qualitative direct contact method referred to as the 'drop on' technique, and a quantitative 'viable count' method.

\section{'Drop on' technique}

$S$. aureus cells were spread evenly over cold blood agar plates (Columbia base $+5 \%$ (v/v) horse blood; Oxoid Ltd, UK). The cationic worm gel and the non-ionic worm gel (control) were each cooled on ice until liquefied and $20 \mu \mathrm{l}$ droplets were applied directly to the cold $S$. aureus lawns using chilled micropipet tips. Plates were then incubated overnight at $37^{\circ} \mathrm{C}$ to allow bacterial growth to occur.

\section{'Viable count' assay}

To $S$. aureus in a cold Eppendorf tube was added $100 \mu$ l of icecold cationic or non-ionic worm gel (or phosphate-buffered saline), then each tube were allowed to warm up to room temperature in order to induce copolymer gelation. After an appropriate incubation period at room temperature, tubes were returned to an ice bath to induce degelation. Ice-cold aqueous PBS solution $(1.0 \mathrm{ml})$ was then added to each tube, vortexmixed and immediately serially-diluted ten-fold using cold PBS. $10 \mu \mathrm{l}$ aliquots of each dilution were spotted in duplicate onto blood agar plates and incubated at room temperature overnight to allow growth of surviving bacteria and the resulting colonies were counted. All experiments were conducted in duplicate.

\section{Polymer characterisation}

${ }^{\mathbf{1}} \mathbf{H}$ NMR spectroscopy. All NMR spectra were recorded using a $400 \mathrm{MHz}$ Bruker Avance-400 spectrometer at $298 \mathrm{~K}$ with 64 scans being averaged per spectrum.

\section{DMF gel permeation chromatography (GPC)}

The PGMA macro-CTA and PGMA-PHPMA diblock copolymer molecular weights and polydispersities were determined using a DMF GPC set-up operating at $60{ }^{\circ} \mathrm{C}$ comprising two Polymer Laboratories PL gel $5 \mu \mathrm{m}$ Mixed-C columns connected in series to a Varian 390-LC multi-detector suite (refractive index detector only) and a Varian 290-LC pump injection module. The GPC eluent was HPLC-grade DMF containing $10 \mathrm{mM} \mathrm{LiBr}$ at a flow rate of $1.0 \mathrm{~mL} \mathrm{~min}^{-1}$. DMSO was used as a flow-rate marker. Calibration was conducted using a series of ten nearmonodisperse poly(methyl methacrylate) standards $\left(M_{\mathrm{n}}=625\right.$ to $\left.618000 \mathrm{~g} \mathrm{~mol}^{-1}\right)$. Chromatograms were analysed using Varian Cirrus GPC software (version 3.3).

\section{Aqueous GPC}

Aqueous GPC was used to characterise the series of PQDMA macro-CTAs. The GPC protocol involved using an Agilent 1260 Infinity series degasser and pump, $8 \mu \mathrm{m}$ Agilent PL Aquagel$\mathrm{OH} 30$ and $8 \mu \mathrm{m}$ Agilent PL Aquagel-OH 40 columns, and both a UV and an RI detector. The eluent was an acidic aqueous buffer ( $\mathrm{pH}$ 2) containing $0.50 \mathrm{M}$ acetic acid, 0.30 $\mathrm{M} \mathrm{NaH}_{2} \mathrm{PO}_{4}$ and acidified with $\mathrm{HCl}$ at a flow rate of $1.0 \mathrm{ml} \mathrm{min} \mathrm{m}^{-1}$. Calibration was achieved using a series of near-monodisperse poly(ethylene oxide) standards with $M_{\mathrm{n}}$ values ranging from 1080 to $905000 \mathrm{~g} \mathrm{~mol}^{-1}$.

\section{Dynamic light scattering (DLS)}

The intensity-average hydrodynamic diameter of diblock copolymer nanoparticles was determined by DLS using a Malvern Zetasizer NanoZS instrument via the Stokes-Einstein equation, which assumes perfectly monodisperse, non-interacting spheres. Aqueous $0.01 \% \mathrm{w} / \mathrm{v}$ copolymer dispersions were analysed using disposable plastic cuvettes, and data were averaged over three consecutive runs. Deionised water was used to dilute each dispersion and ultra-filtered through a $0.20 \mu \mathrm{m}$ membrane to remove dust prior to use.

\section{Aqueous electrophoresis}

Zeta potentials for diblock copolymer nanoparticles were analysed using a Malvern Zetasizer Nano ZS instrument. All measurements were conducted in the presence of $1 \mathrm{mM} \mathrm{KCl}$, with either dilute $\mathrm{NaOH}$ or $\mathrm{HCl}$ being used for $\mathrm{pH}$ adjustment as required.

\section{Transmission electron microscopy (TEM)}

Copper/palladium TEM grids (Agar Scientific, UK) were surface-coated to yield a thin film of amorphous carbon. The grids were then plasma glow-discharged for 30 seconds to create a hydrophilic surface. A small volume $(10 \mu \mathrm{L})$ of a dilute aqueous copolymer dispersion was placed on a freshly-prepared grid for 20 seconds and then carefully blotted with filter paper to remove excess solution. To stain the aggregates, a $0.75 \% \mathrm{w} / \mathrm{v}$ uranyl formate solution $(10 \mu \mathrm{L})$ was placed on the sample-loaded grid for 15 seconds and then carefully blotted to remove excess stain. The grids were then dried using a vacuum hose. Imaging was performed using a FEI Tecnai Spirit microscope fitted with a Gatan 1KMS600CW CCD camera operating at $80 \mathrm{KV}$.

\section{Rheology measurements}

An AR-G2 rheometer equipped with a variable temperature Peltier plate and a $40 \mathrm{ml} 2^{\circ}$ aluminium cone was used for all experiments. The loss modulus $\left(G^{\prime \prime}\right)$ and storage modulus $\left(G^{\prime}\right)$ were measured as a function of percentage strain, angular frequency and temperature to assess the critical gelation temperature (CGT) and gel moduli $\left(G^{\prime}\right.$ and $\left.G^{\prime \prime}\right)$. Percentage strain sweeps were conducted at $25{ }^{\circ} \mathrm{C}$ using a fixed angular frequency of $1.0 \mathrm{rad} \mathrm{s}^{-1}$. Angular frequency sweeps were conducted at $25{ }^{\circ} \mathrm{C}$ using a constant percentage strain of $1.0 \%$. Temperature sweeps were conducted using a constant percentage strain of $1.0 \%$ and a constant angular frequency of $1.0 \mathrm{rad}$ $\mathrm{s}^{-1}$. In these latter experiments, the temperature was lowered from 25 to $2{ }^{\circ} \mathrm{C}$ at $1.0^{\circ} \mathrm{C}$ intervals, allowing $1 \mathrm{~min}$ for thermal equilibrium in each case. After $5 \mathrm{~min}$ at $2^{\circ} \mathrm{C}$, the dispersion was heated up to $25^{\circ} \mathrm{C}$ in $1.0^{\circ} \mathrm{C}$ intervals. 


\section{Results and discussion}

In this study, we revisit our earlier PISA formulation reported by Semsarilar and co-workers ${ }^{42}$ in order to prepare stericallystabilised cationic diblock copolymer nanoparticles via RAFT aqueous dispersion polymerisation using a binary mixture of macro-CTAs. More specifically, a binary mixture of PQDMA (cationic) and PGMA (non-ionic) macro-CTAs are chainextended simultaneously using HPMA to produce either spheres, worms or vesicles (see Fig. 1). Initially, three PQDMA macro-CTAs with differing mean degrees of polymerisation were synthesised by RAFT solution polymerisation using a 9:1 ethanol/water mixture. PETTC was used as the RAFT agent and 4,4'-azobis(4-cyanopentanoic acid) (ACVA) was utilised as the free radical initiator at a $\mathrm{CTA} /$ initiator molar ratio $=5.0$. Following QDMA polymerisation at $30 \% \mathrm{w} / \mathrm{w}$ solids and $70{ }^{\circ} \mathrm{C}$ for $3 \mathrm{~h}$, any unreacted monomer was removed via precipitation into excess acetonitrile. ${ }^{1} \mathrm{H}$ NMR studies confirmed that the three PQDMA macro-CTAs had mean degrees of polymerisation (DP) of 26, 48 and 95 respectively, while aqueous GPC analysis ( $v s$. PEO calibration standards) indicated that each macro-CTA had an $M_{\mathrm{w}} / M_{\mathrm{n}}$ of less than 1.25 (see Fig. S1 $\dagger$ ).

It is well-known that using a polyelectrolyte as the sole stabiliser block during the PISA synthesis of AB diblock copolymer nanoparticles in aqueous solution invariably results in only spherical morphologies being obtained as a result of the strong electrostatic repulsion between the charged stabiliser chains. ${ }^{24,27,41,42}$ To examine this phenomenon, a range of $\mathrm{PQDMA}_{26}-\mathrm{PHPMA}_{z}$ diblock copolymer nanoparticles were prepared at $10 \% \mathrm{w} / \mathrm{w}$ solids using RAFT aqueous dispersion polymerisation, where $z$ was varied from 100 to 500. DLS and TEM studies confirmed that indeed only spherical nanoparticles with mean diameters ranging from 100 to $300 \mathrm{~nm}$ could be produced (see Fig. S2 $\dagger$ ). Previously, it has been shown that increasing the copolymer concentration in RAFT aqueous dispersion formulations using either non-ionic or zwitterionic steric stabiliser blocks can lead to the formation of so-called 'higher order' morphologies such as worms or vesicles. ${ }^{23,34}$ However, attempts to synthesise $\mathrm{PQDMA}_{26}-\mathrm{PHPMA}_{z}$ diblock copolymers at $20 \% \mathrm{w} / \mathrm{w}$ solids only resulted in the formation of highly viscous solutions that appeared to be rather polydisperse after dilution for DLS studies.

To evaluate using a binary mixture of macro-CTAs as reported by Semsarilar and co-workers, ${ }^{41,42}$ a non-ionic PGMA macro-CTA was synthesised according to a previously reported protocol. $^{47}$ More specifically, a PGMA $_{62}$ macro-CTA $\left(M_{\mathrm{n}}=\right.$ $16500 ; M_{\mathrm{w}} / M_{\mathrm{n}}=1.12$ ) was prepared by RAFT solution polymerisation of GMA in ethanol using a PETTC RAFT agent and ACVA initiator at a PETTC/ACVA molar ratio of 5.0.

Using various combinations of the PQDMA and PGMA macro-CTAs, several series of $\left([1-n] \mathrm{PGMA}_{x}+[n] \mathrm{PQDMA}_{y}\right)-$ PHPMA $_{z}$ diblock copolymer nanoparticles were synthesised by RAFT aqueous dispersion polymerisation (see Fig. 1). As reported previously, ${ }^{41,42}$ diluting the cationic PQDMA macroCTA with the non-ionic PGMA macro-CTA leads to entropic mixing with the stabiliser coronal layer, which enables fine control of the surface charge density in the resulting nanoparticles. In such a PISA formulation, several variables require optimisation, including (i) the DPs $(x, y)$ of the PGMA and PQDMA of the stabiliser blocks, (ii) the PHPMA core-forming DP $(z)$ and (iii) the PQDMA/PGMA molar ratio $(n)$. In addition, the copolymer concentration is often found to be an important parameter, with pure worm and vesicle phases typically being observed only at higher concentrations. ${ }^{23,34}$ To minimise the parameter space to be explored for this binary mixture of macro-CTAs formulation, all PISA syntheses were conducted at $20 \% \mathrm{w} / \mathrm{w}$ solids. It is also worth emphasising that no added salt was required, whereas Semsarilar et al. ${ }^{41,42}$ reported that addition of $0.30 \mathrm{M} \mathrm{NaCl}$ was necessary to screen the unfavourable electrostatics in order to access higher morphologies.

The first step in optimising this PISA formulation was to fix the DP of the non-ionic PGMA stabiliser and vary the DP of the PQDMA stabiliser in order to examine the cationic character of the resulting nanoparticles. More specifically, RAFT solution polymerisation was utilised to prepare a PGMA $_{62}$ macro-CTA and three PQDMA macro-CTAs with DPs (or $y$ ) of 26, 48 or 95, respectively. A series of PISA formulations were then conducted, targeting a fixed PHPMA core-forming block DP (or $z$ ) of 200 using a PQDMA mol fraction, $n$, of 0.10 (i.e. $10 \mathrm{~mol} \%$ PQDMA). Fig. 2 shows the TEM images and aqueous electrophoresis data obtained for the resulting nanoparticles prepared with the general formula $\left(0.9 \mathrm{PGMA}_{62}+0.1 \mathrm{PQDMA}_{y}\right)-$ PHPMA $_{200}$ where $y=26,48$ or 95. Purely non-ionic PGMA $_{62}-$ PHPMA $_{200}$ diblock copolymer nanoparticles with no PQDMA present (i.e. $n=0$ ) were also synthesised as a control. TEM analysis confirmed that all of the nanoparticles had the same characteristic worm-like morphology. The zeta potential $v s . \mathrm{pH}$

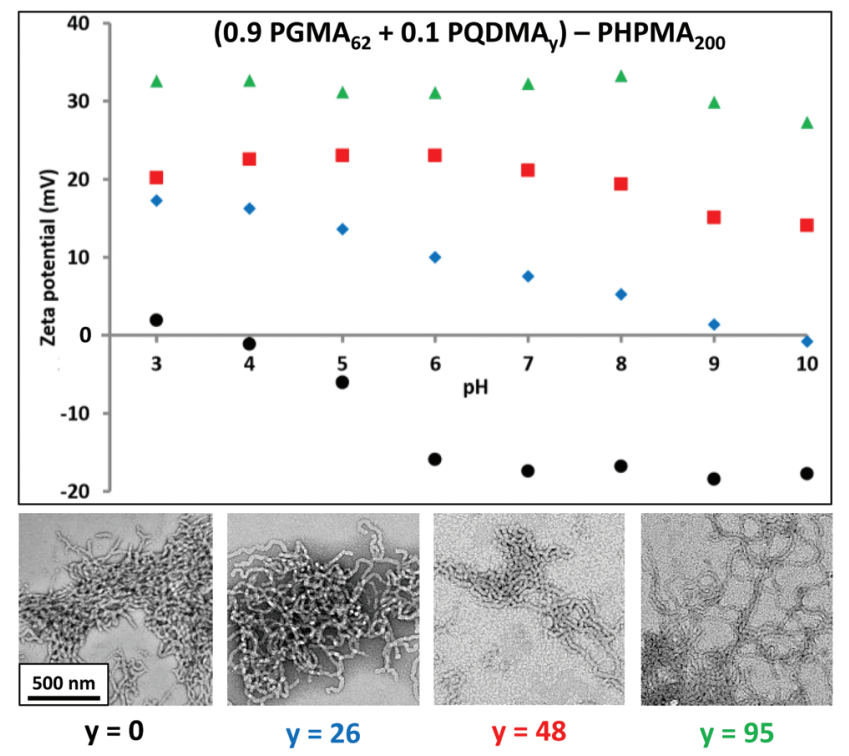

Fig. 2 Zeta potential vs. pH curves and corresponding transmission electron microscopy images recorded for diblock copolymer nanoparticles with the general formula $\left(0.9 \mathrm{PGMA}_{62}+0.1 \mathrm{PQDMA} \mathrm{A}_{y}\right)-$ PHPMA $_{200}$ where $y=0,26,48$ or 95 . The scale bar applies to all images. 
curve for the non-ionic PGMA $_{62}-$ PHPMA $_{200}$ diblock copolymer worms indicated that these nanoparticles possessed essentially no surface charge at around $\mathrm{pH} 4$, but became weakly anionic $(-15$ to $-18 \mathrm{mV})$ above $\mathrm{pH}$ 6. This is attributed to ionisation of the terminal carboxylic acid group $\left(\mathrm{p} K_{\mathrm{a}} \sim 4.7\right)^{47}$ located at the end of the stabiliser chains. Incorporating $10 \mathrm{~mol} \%$ of a relatively short $\mathrm{PQDMA}_{26}$ stabiliser (i.e. $\quad\left(0.9 \mathrm{PGMA}_{62}+\right.$ $\left.0.1 \mathrm{PQDMA}_{26}\right)$ - $\mathrm{PHPMA}_{200}$ ) leads to weakly cationic character (around $+17 \mathrm{mV}$ at $\mathrm{pH} 3$, gradually reducing to $0 \mathrm{mV}$ at around $\mathrm{pH}$ 9.5). Clearly, the cationic nature of the quaternised $\mathrm{PQDMA}_{26}$ stabiliser is partially shielded by the longer nonionic PGMA $_{62}$ stabiliser. The worms become significantly more cationic $(+15$ to $+23 \mathrm{mV})$ over the entire $\mathrm{pH}$ range when the $\mathrm{PQDMA}_{26}$ stabiliser is replaced with $\mathrm{PQDMA}_{48}$. As expected, using the $\mathrm{PQDMA}_{95}$ stabiliser produces the most cationic worms (around $+30 \mathrm{mV}$ up to $\mathrm{pH} 9$ ), since these longer chains protrude beyond the non-ionic PGMA $_{62}$ stabiliser chains. It is noteworthy that this represents a marked improvement over the electrophoretic data reported by Semsarilar and coworkers, who obtained cationic worms only at relatively low $\mathrm{pH}^{42}$ Clearly, increasing the cationic stabiliser block DP beyond that of the non-ionic block DP enables the cationic character of worms (and presumably other copolymer morphologies) to be maximised. Thus this design principle was adopted for the remaining part of the current study, which was focused on exploring the judicious combination of the PQDMA $_{95}$ and PGMA $_{63}$ stabiliser blocks. The remaining two variables in this system, namely the PHPMA core-forming DP $(z)$, and the $\mathrm{PQDMA}_{95} / \mathrm{PGMA}_{62}$ stabiliser molar ratio $(n)$ were systematically varied in order to construct a phase diagram based on TEM and DLS studies, see Fig. 3. Each data point on this phase diagram corresponds to an individual PISA synthesis for which a final HPMA conversion of at least 99\% was achieved. First, a series of non-ionic PGMA $_{62}-$ PHPMA $_{z}$ diblock copolymer nanoparticles were prepared. Determining the



Fig. 3 Phase diagram constructed for a series of diblock copolymer nanoparticles of general formula ([1 - n] PGMA $62+[n]$ PQDMA $\left._{95}\right)-$ $\mathrm{PHPMA}_{z}$ prepared by RAFT aqueous dispersion polymerisation of HPMA at $20 \% \mathrm{w} / \mathrm{w}$ solids. $\mathrm{S}=$ spheres, $\mathrm{W}=$ worms, $\mathrm{V}=$ vesicles, $\mathrm{S}+\mathrm{W}=$ mixed phase of spheres plus worms, $\mathrm{W}+\mathrm{V}=$ mixed phase of worms plus vesicles. precise PHPMA DP corresponding to pure phases of spheres, worms or vesicles provided a good starting point for the gradual introduction of the cationic $\mathrm{PQDMA}_{95}$ auxiliary stabiliser. Furthermore, these $\mathrm{PGMA}_{62}-\mathrm{PHPMA}_{z}$ diblocks could be readily characterised by DMF GPC. It was found that the PGMA $_{62}$ macro-CTA $\left(M_{\mathrm{w}} / M_{\mathrm{n}}=1.12\right)$ could be chain-extended to produce a $\mathrm{PGMA}_{62}-\mathrm{PHPMA}_{450}$ diblock copolymer $\left(M_{\mathrm{w}} / M_{\mathrm{n}}=\right.$ 1.17), see Fig. S3.† Inspecting Fig. S3, $\dagger$ a high molecular weight shoulder can be observed, which has been previously attributed to light branching caused by the relatively low level $(<0.30 \mathrm{~mol} \%)$ of dimethacrylate impurity in HPMA monomer. ${ }^{22,33}$ This feature becomes more prominent as the target DP of the PHPMA core-forming block is increased, but it is emphasised that this has no discernible effect on the final particle morphology. ${ }^{22,23,33}$ This suggests reasonably good living character, as expected for such RAFT-mediated PISA syntheses. ${ }^{33}$ Unfortunately, it was not feasible to characterise the cationic diblock copolymer nanoparticles prepared using binary mixtures of macro-CTAs as there is no suitable common solvent that dissolves PQDMA, PGMA and PHPMA. However, given the relatively high blocking efficiency exhibited by the PGMA $_{62}$ macro-CTA, and our previous reports describing the use of a wide range of macro-CTAs to polymerise HPMA via RAFT aqueous dispersion polymerisation, ${ }^{48}$ reasonably good living character should be expected under such conditions when using such a binary mixture of methacrylic macro-CTAs. From the phase diagram shown in Fig. 3, pure phases of spheres ( $z=100$ to 125 ), worms ( $z=150$ to 200 ) and vesicles $(z=225$ to 500$)$ can be clearly identified when using the reference PGMA $_{62}-$ PHPMA $_{z}$ PISA formulation. Crossing the phase diagram horizontally from left to right, the effect of systematically varying the proportion of PQDMA $_{95}$ macro-CTA can be assessed. For a fixed PHPMA core block DP (e.g. 350), increasing the mol fraction $(n)$ of this cationic stabiliser typically results in a gradual change in copolymer morphology from vesicles to spheres. This trend holds for all PHPMA DPs from 150 to 500 , but for a DP of 100 only spheres can be obtained, regardless of the value of $n$. Fig. 4 shows representative TEM images used to assign the morphology of a series of diblock copolymer nanoparticles with the general formula $([1-n]$ $\left.\mathrm{PGMA}_{62}+[n] \mathrm{PQDMA}_{95}\right)-\mathrm{PHPMA}_{250}$, where $n$ ranges from 0.0 to 0.50 . When no cationic $\mathrm{PQDMA}_{95}$ macro-CTA is present (i.e. if $n=0$ ), a well-defined vesicular morphology is observed. However, the addition of just 10 mol\% $(n=0.10)$ PQDMA $_{95}$ stabiliser results in the formation of a mixed phase comprising vesicles and worms, while a mixture of worms and spheres is observed for $n=0.20$ to 0.30 and only spheres are obtained at $n=0.40$.

Considering the effect of varying the PHPMA core-forming block DP from 100 to 500 at a fixed PQDMA ${ }_{95}$ stabiliser is also instructive. For example, when no cationic stabiliser is present $(n=0)$, a PHPMA DP of just 225 results in a pure vesicle morphology. However, when $n=0.10$ there is a gradual change from spheres $(\mathrm{DP}=100)$ to worms ( $\mathrm{DP}=150$ to 200$)$ to a mixed worm/vesicle phase ( $\mathrm{DP}=225$ to 300 ) to finally a pure vesicle phase ( $\mathrm{DP}=350$ to 500$)$. Clearly, introducing a polyelectrolytic 



Fig. 4 Representative transmission electron microscopy images obtained for selected diblock copolymer nanoparticles of general formula $\left([1-n]\right.$ PGMA $_{62}+[n]$ PQDMA $\left.{ }_{95}\right)-$ PHPMA $_{250}$ prepared by RAFT aqueous dispersion polymerisation of HPMA at $20 \% \mathrm{w} / \mathrm{w}$ solids when $n$ is varied from 0 to 0.30 . The scale bar shown applies to all images. A pure vesicle phase is obtained when $n=0$, a worms + vesicles mixed phase is observed when $n=0.10$, a spheres + worms mixed phase is produced when $n=0.2-0.3$ and a pure sphere phase is found when $n=$ $0.40-0.50$

stabiliser block leads to greater inter-chain repulsive forces, which makes so-called higher order morphologies (i.e. worms or vesicles) more difficult to access. Furthermore, larger mixed phase regions are produced as the proportion of $\mathrm{PQDMA}_{95}$ is increased. For example, for $n=0.20$ (or $20 \mathrm{~mol}_{0} \mathrm{PQDMA}_{95}$ stabiliser), no pure worm phase could be obtained, and for a rather broad PHPMA DP range of 150 to 400, only mixed phases could be identified prior to the eventual formation of a pure vesicle phase at a DP of 450 . No pure vesicle phase was accessible for $n=0.30$, while at $n=0.50$ inter-chain repulsion becomes so strong that only kinetically-trapped spheres can be produced even when targeting a DP of 500. This is comparable to observations for $\mathrm{PQDMA}_{95}-\mathrm{PHPMA}_{z}$ diblock copolymer nanoparticles (i.e. in the absence of any non-ionic $\mathrm{PGMA}_{62}$ stabiliser).

Fig. 5 shows the corresponding zeta potential $v s$. $\mathrm{pH}$ curves obtained for a series of diblock copolymer nanoparticles with

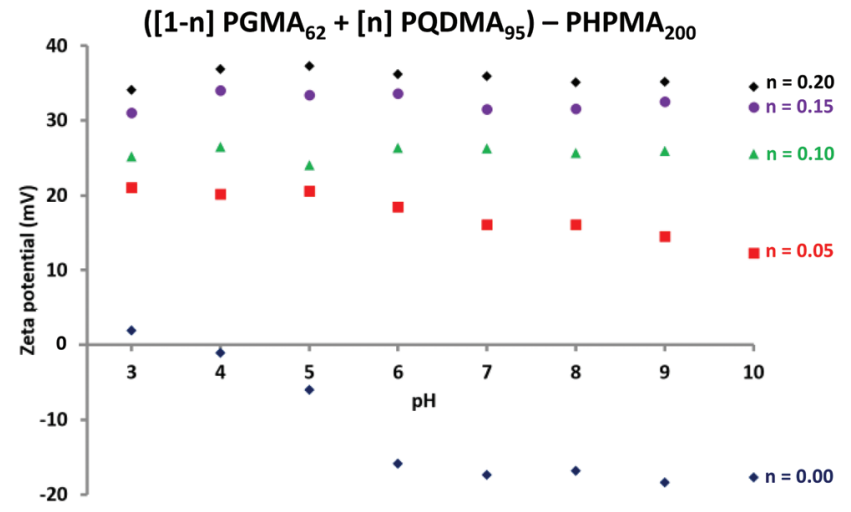

Fig. 5 Zeta potential vs. $\mathrm{pH}$ curves recorded for diblock copolymer nanoparticles of general formula $\left([1-n] \mathrm{PGMA}_{62}+[n] \mathrm{PQDMA}_{95}\right)-$ $\mathrm{PHPMA}_{200}$ when $n$ is varied from 0 to 0.20 .

the general formula $\left([1-n]\right.$ PGMA $_{62}+[n]$ PQDMA $\left._{95}\right)-$ PHPMA $_{200}$, i.e. for a fixed PHPMA DP of 200 where $n$ is varied from 0 to 0.20 . As the proportion of PQDMA ${ }_{95}$ is increased, the nanoparticle zeta potential gradually becomes less anionic/ more cationic over the whole $\mathrm{pH}$ range. For example, at $\mathrm{pH} 9$ the zeta potential increases monotonically from $-20 \mathrm{mV}$ when no $\mathrm{PQDMA}_{95}$ is present (i.e. $n=0$ ), to $+35 \mathrm{mV}$ for $n=0.20$. Clearly, using a binary mixture of macro-CTAs enables finetuning of the cationic character of the nanoparticles. Furthermore, as the PQDMA $_{95}$ stabiliser is longer than the non-ionic PGMA $_{62}$ stabiliser, strongly cationic zeta potentials can be maintained over the entire $\mathrm{pH}$ range. Given the phase diagram shown in Fig. 3, then in principle judicious variation of the mol fraction of the cationic stabiliser block $(n)$ and the target DP of the PHPMA core-forming block $(z)$, enables nanoparticles with a desired copolymer morphology and zeta potential to be targeted reproducibly.

We have previously reported that PGMA-PHPMA diblock copolymer worms form relatively soft free-standing gels at high concentration due to multiple inter-worm contacts. $^{35,36,38}$ These worms are thermo-sensitive, with degelation occurring on cooling below the critical gelation temperature (CGT) as a result of a worm-to-sphere transition. If performed above the critical gelation concentration (CGC), this transition is fully reversible: multiple sphere-sphere fusion commences on returning to room temperature, the original worms are reformed and a new gel is produced with essentially identical physical properties to that of the original gel. This thermoreversible enables convenient sterilisation of the worm gels via cold ultrafiltration, ${ }^{35}$ which suggests various biomedical applications. $^{39,40}$ It is well-known that many cationic polymers exhibit anti-bacterial properties. ${ }^{44,49-54}$ In principle, incorporating appreciable cationic character into such worm gels might confer anti-microbial properties. ${ }^{45}$ From the phase diagram constructed in Fig. 3, worm phase space can be reproducibly targeted by optimising the PISA formulation, e.g. by targeting a PHPMA DP $(z)$ of 150-200 when utilising a PQDMA $_{95}$ mol fraction of $0<n \leq 0.15$ (when $n=0.20$ a gel is 
also obtained, but TEM analysis indicates that this sample comprises a mixture of worms and spheres, see Fig. S4†). Such aqueous cationic worms form free-standing gels when prepared directly at $20 \% \mathrm{w} / \mathrm{w}$ solids. After their PISA synthesis at $20 \% \mathrm{w} / \mathrm{w}$, these worm gels were serially diluted using deionised water until degelation was observed. This copolymer concentration was taken to be the critical gelation concentration (CGC). The CGC of the reference non-ionic $\mathrm{PGMA}_{62}$ PHPMA $_{200}$ diblock copolymer worms was estimated to be $5.0 \%$ $\mathrm{w} / \mathrm{w}$, which is in fairly good agreement with previous work. ${ }^{36}$ The corresponding CGC values for copolymers containing 5 ,

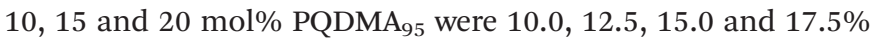
w/w, respectively (see Fig. S4 $\dagger$ ). According to Fig. 5, increasing the proportion of $\mathrm{PQDMA}_{95}$ stabiliser results in a systematic increase in nanoparticle zeta potential. Thus the monotonic increase in CGC is most likely the result of weaker inter-worm interactions as the increasing cationic character leads to greater electrostatic repulsion between neighbouring worms. This also leads to a gradual reduction in the storage modulus $\left(G^{\prime}\right)$ for this series of worm gels.

To investigate how the introduction of cationic character affects the thermo-responsive properties of the worm gels, a $\left(0.95 \mathrm{PGMA}_{62}+0.05 \mathrm{PQDMA}_{95}\right)-\mathrm{PHPMA}_{200}$ diblock copolymer was diluted to $12.5 \% \mathrm{w} / \mathrm{w}$ and subjected to variable temperature rheology studies, see Fig. 6. The aqueous dispersion, which formed a soft free-standing gel at $25^{\circ} \mathrm{C}$, was cooled to $2{ }^{\circ} \mathrm{C}$ at $1{ }^{\circ} \mathrm{C}$ intervals before warming up to $25^{\circ} \mathrm{C}$ using the same temperature ramp. Both temperature sweeps were conducted at a strain of $1.0 \%$ and an angular frequency of $1.0 \mathrm{rad}$ $\mathrm{s}^{-1}$. This particular frequency was selected because $\mathrm{G}^{\prime}$ exceeds $\mathrm{G}^{\prime \prime}$ at $25{ }^{\circ} \mathrm{C}$. This indicates gel formation under these conditions, while the strain sweep conducted at this same frequency confirmed that an applied strain of $1.0 \%$ falls well within the linear viscoelastic regime (see Fig. S5†). Inspecting the cooling data (red and blue open circles) shown in Fig. 6, the storage modulus $\left(G^{\prime}\right)$ initially exceeds the loss modulus $\left(G^{\prime \prime}\right)$ at $25^{\circ} \mathrm{C}$, which suggests the formation of a viscoelastic

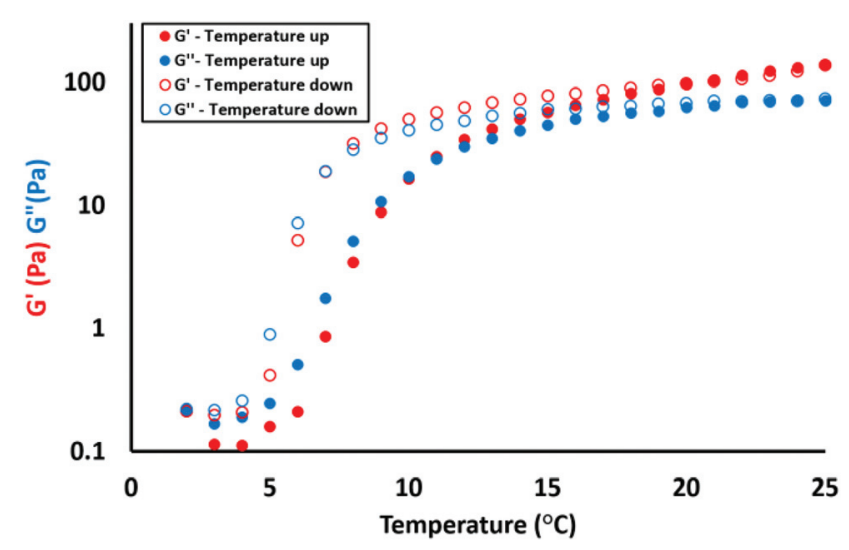

Fig. 6 Temperature-dependent rheology studies for a $12.5 \% \mathrm{w} / \mathrm{w}$ aqueous dispersion of cationic diblock copolymer worms of general formula (0.95PGMA $\left.62+0.05 P Q D M A_{95}\right)-$ PHPMA $_{200}$. The angular frequency was held constant at $1.0 \mathrm{rad} \mathrm{s}^{-1}$ at an applied strain of $1.0 \%$. gel. Degelation is observed at a critical gelation temperature (CGT) of $7^{\circ} \mathrm{C}$, which corresponds to the point where the $G^{\prime \prime}$ (open blue circles) and $G^{\prime}$ (open red circles) curves intersect. Below this CGT, the dispersion behaves as a free-flowing liquid. On heating the cold dispersion (red and blue filled circles), the $G^{\prime}$ (filled red circles) and $G^{\prime \prime}$ (filled blue circles) curves cross at $11{ }^{\circ} \mathrm{C}$, indicating mild hysteresis. This is because the dissociation of worms to form spheres is relatively rapid, whereas the multiple sphere fusion required to reform worms is a highly cooperative process, which requires a longer time scale. Such hysteresis can be minimised by either warming at a slower rate or working at a higher copolymer concentration to aid the sphere-to-worm transition. Nevertheless the rheology data presented in Fig. 6 confirms that this particular cationic worm gel $(+20 \mathrm{mV}$ at $\mathrm{pH}$ 6) exhibits essentially the same thermo-responsive behaviour as the non-ionic reference PGMA $_{62}-\mathrm{PHPMA}_{200}$ worm gel (see Fig. S6†). Variable temperature ${ }^{1} \mathrm{H}$ NMR spectroscopy studies performed by Blanazs et al. ${ }^{35}$ suggest that the thermo-sensitive core-forming PHPMA block becomes more hydrated on cooling. This leads to a subtle increase in the packing parameter for the copolymer chains, which in turn induces the worm-to-sphere transition. ${ }^{55}$ Although this cationic worm gel is thermo-responsive, its gel strength of $137 \mathrm{~Pa}$ is significantly lower than the $G^{\prime}$ of $185 \mathrm{~Pa}$ observed for the non-ionic PGMA $_{62}-\mathrm{PHPMA}_{200}$ worm gel at $25^{\circ} \mathrm{C}$ (see Fig. S6 $\dagger$ ). Furthermore, increasing the proportion of PQDMA $_{95}$ from 5 to $10 \mathrm{~mol} \%(n=0.05$ to $n=0.10)$ led to irreversible thermally-triggered degelation; regelation was no longer observed on warming from $2{ }^{\circ} \mathrm{C}$ to $20{ }^{\circ} \mathrm{C}$ on the time scale of the rheology experiment. This is consistent with our hypothesis that greater cationic character reduces the gel strength.

It has been widely reported that cationic nanoparticles often exhibit useful anti-microbial activity. ${ }^{43-46}$ Thus the antimicrobial properties of the cationic thermo-responsive $\left(0.95\right.$ PGMA $\left._{62}+0.05 \mathrm{PQDMA}_{95}\right)-\mathrm{PHPMA}_{200}$ worm gel were investigated. Using a direct contact assay between bacteria and the $12.5 \% \mathrm{w} / \mathrm{w}$ copolymer gel (the so-called 'drop on' technique), no growth of $S$. aureus S235 was observed beneath the cationic worm gel (see Fig. 7A), whereas bacterial growth was clearly discernible underneath the non-ionic copolymer

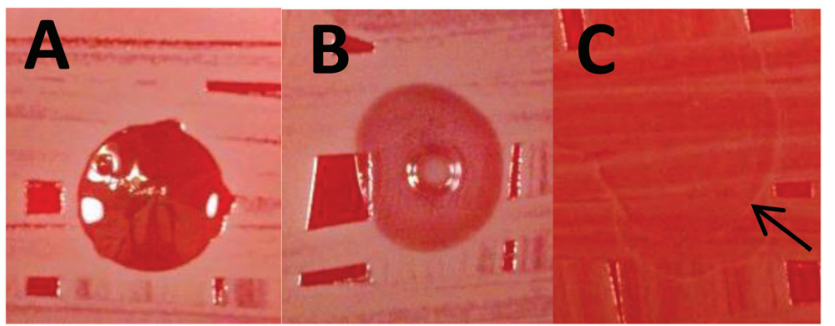

Fig. 7 Images obtained for lawns of S. aureus S235 on agar plates upon which drops of either copolymer worm gels or PBS were applied prior to incubation at $37{ }^{\circ} \mathrm{C}$ overnight: (A) cationic worm gel, (B) non-ionic worm gel, (C) PBS. Bacterial growth was observed when employing the non-ionic worm gel and the PBS control, but not for the cationic worm gel. Arrow shows the location of the PBS droplet. 


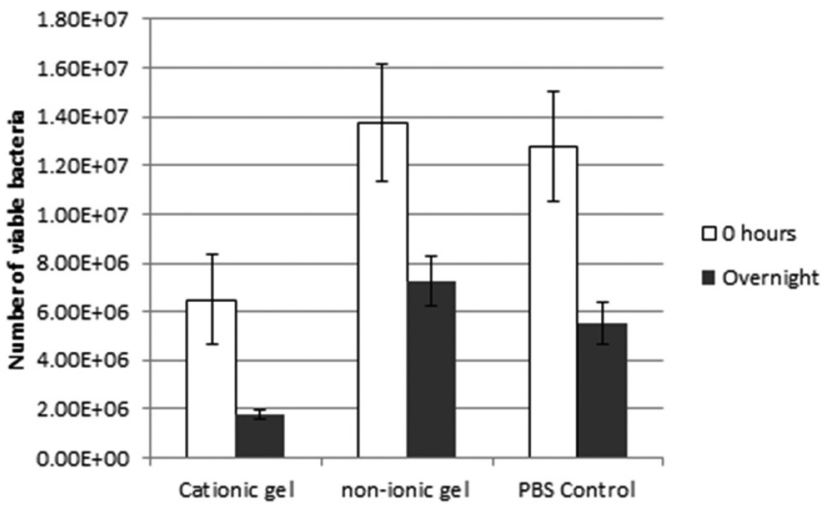

Fig. 8 S. aureus S235 incubated with cationic and non-ionic worm gels for varying times under non-growth conditions. Data are viable counts per $\mathrm{ml}$ of surviving bacteria; error bars are \pm standard error.

control gel (and also where the aqueous PBS droplet had been placed), see Fig. 7B and C, respectively. This suggests a bacteriostatic effect for the cationic worm gel. S. aureus S235 was also exposed to either the cationic worm gel, the non-ionic worm gel or to PBS at room temperature for $18 \mathrm{~h}$ under nongrowth conditions. The number of surviving, cultivable bacteria was assessed by separating the bacteria from the worm gels by cooling to induce degelation, followed by dilution using cold PBS (see Fig. 8). No nutrients were available during this period and the number of cultivable bacteria declined in PBS over that period by $56 \pm$ se $16 \%$. However, exposure to the cationic worm gel resulted in a reduction in viable bacteria count of $73 \pm$ se $10 \%$, which was significantly greater ( $p=0.04, t$-test) than that obtained on exposure of the bacteria to the control non-ionic worm gel (48 \pm se $14 \%)$. These preliminary data suggest a mild bactericidal effect for the cationic worm gel.

\section{Conclusions}

A series of cationic diblock copolymer nano-objects with the general formula $\left([1-n] \mathrm{PGMA}_{x}+[n] \mathrm{PQDMA}_{y}\right)-\mathrm{PHPMA}_{z}$ has been synthesised at $20 \% \mathrm{w} / \mathrm{w}$ solids via RAFT aqueous dispersion polymerisation of HPMA utilising a binary mixture of non-ionic and cationic macro-CTAs. If the cationic PQDMA stabiliser is longer than the non-ionic PGMA stabiliser, the resulting diblock copolymer nanoparticles retain their cationic character over the entire $\mathrm{pH}$ range. By fixing the PGMA and PQDMA DPs at 62 and 95 respectively, phase boundaries can be identified for cationic spheres, worms and vesicles when systematically varying (i) the PQDMA mol fraction (n) and (ii) the mean DP of the core-forming PHPMA block $(z)$. Furthermore, increasing the proportion of cationic stabiliser in these diblock copolymer nano-objects at a fixed PHPMA DP enables the zeta potential to be adjusted at a given $\mathrm{pH}$. However, the greater cationic character observed for PQDMA-rich formulations also tends to favour a spherical morphology. Variable temperature rheology studies indicate that a thermo-respon- sive cationic worm gel exhibiting a zeta potential of $+20 \mathrm{mV}$ and a storage modulus of 137 Pa can be prepared when using 5 mol\% PQDMA stabiliser in the PISA formulation. Moreover, this soft free-standing gel at $25{ }^{\circ} \mathrm{C}$ undergoes degelation on cooling to $7{ }^{\circ} \mathrm{C}$ as a result of a worm-to-sphere transition and this order-order transition is fully reversible at $12.5 \% \mathrm{w} / \mathrm{w}$ solids. Finally, these cationic thermo-responsive gels were shown to be both bacteriostatic and mildly bactericidal against $S$. aureus, whereas the non-ionic reference worm gel exhibited no discernible anti-microbial activity.

\section{Acknowledgements}

We thank P \& G (Belgium) for financial support. SPA acknowledges EPSRC (EP/J007846/1) and ERC grants (PISA 320372).

\section{Notes and references}

1 L. F. Zhang and A. Eisenberg, Science, 1995, 268, 17281731.

2 Y. Geng, P. Dalhaimer, S. Cai, R. Tsai, M. Tewari, T. Minko and D. E. Discher, Nat. Nanotechnol., 2007, 2, 249-255.

3 Y. Y. Won, H. T. Davis and F. S. Bates, Science, 1999, 283, 960-963.

4 X. Wang, G. Guerin, H. Wang, Y. Wang, I. Manners and M. A. Winnik, Science, 2007, 317, 644-647.

5 T. Gaedt, N. S. Ieong, G. Cambridge, M. A. Winnik and I. Manners, Nat. Mater., 2009, 8, 144-150.

6 N. Petzetakis, A. P. Dove and R. K. O'Reilly, Chem. Sci., 2011, 2, 955-960.

7 B. M. Discher, Y. Y. Won, D. S. Ege, J. C. M. Lee, F. S. Bates, D. E. Discher and D. A. Hammer, Science, 1999, 284, 11431146.

8 D. E. Discher and A. Eisenberg, Science, 2002, 297, 967-973.

$9 \mathrm{~J}$. Rodriguez-Hernandez and S. Lecommandoux, J. Am. Chem. Soc., 2005, 127, 2026-2027.

10 G. Battaglia and A. J. Ryan, Nat. Mater., 2005, 4, 869-876.

11 S. Stewart and G. Liu, Angew. Chem., Int. Ed., 2000, 39, 340344.

12 D. Chen, S. Park, J.-T. Chen, E. Redston and T. P. Russell, ACS Nano, 2009, 3, 2827-2833.

13 D. J. Pochan, Z. Y. Chen, H. G. Cui, K. Hales, K. Qi and K. L. Wooley, Science, 2004, 306, 94-97.

14 G. Battaglia and A. J. Ryan, J. Am. Chem. Soc., 2005, 127, 8757-8764.

15 A. Blanazs, M. Massignani, G. Battaglia, S. P. Armes and A. J. Ryan, Adv. Funct. Mater., 2009, 19, 2906-2914.

16 J. Z. Du, Y. Q. Tang, A. L. Lewis and S. P. Armes, J. Am. Chem. Soc., 2005, 127, 17982-17983.

17 S. Perrier and P. Takolpuckdee, J. Polym. Sci., Part A: Polym. Chem., 2005, 43, 5347-5393.

18 G. Moad, E. Rizzardo and S. H. Thang, Polymer, 2008, 49, 1079-1131. 
19 G. Moad, E. Rizzardo and S. H. Thang, Acc. Chem. Res., 2008, 41, 1133-1142.

20 Z. An, Q. Shi, W. Tang, C.-K. Tsung, C. J. Hawker and G. D. Stucky, J. Am. Chem. Soc., 2007, 129, 14493-14499.

21 J. Rieger, C. Grazon, B. Charleux, D. Alaimo and C. Jerome, J. Polym. Sci., Part A: Polym. Chem., 2009, 47, 2373-2390.

22 Y. Li and S. P. Armes, Angew. Chem., Int. Ed., 2010, 49, 4042-4046.

23 A. Blanazs, A. J. Ryan and S. P. Armes, Macromolecules, 2012, 45, 5099-5107.

24 S. Boisse, J. Rieger, K. Belal, A. Di-Cicco, P. Beaunier, M.-H. Li and B. Charleux, Chem. Commun., 2010, 46, 19501952.

25 X. Zhang, S. Boisse, W. Zhang, P. Beaunier, F. D'Agosto, J. Rieger and B. Charleux, Macromolecules, 2011, 44, 41494158.

26 I. Chaduc, W. Zhang, J. Rieger, M. Lansalot, F. D'Agosto and B. Charleux, Macromol. Rapid Commun., 2011, 32, 1270-1276.

27 S. Boisse, J. Rieger, G. Pembouong, P. Beaunier and B. Charleux, J. Polym. Sci., Part A: Polym. Chem., 2011, 49, 3346-3354.

28 W. Zhang, F. D'Agosto, O. Boyron, J. Rieger and B. Charleux, Macromolecules, 2011, 44, 7584-7593.

29 W.-M. Wan and C.-Y. Pan, Polym. Chem., 2010, 1, 14751484.

30 C.-Q. Huang and C.-Y. Pan, Polymer, 2010, 51, 5115-5121.

31 E. R. Jones, M. Semsarilar, A. Blanazs and S. P. Armes, Macromolecules, 2012, 45, 5091-5098.

32 L. A. Fielding, M. J. Derry, V. Ladmiral, J. Rosselgong, A. M. Rodrigues, L. P. D. Ratcliffe, S. Sugihara and S. P. Armes, Chem. Sci., 2013, 4, 2081-2087.

33 A. Blanazs, J. Madsen, G. Battaglia, A. J. Ryan and S. P. Armes, J. Am. Chem. Soc., 2011, 133, 16581-16587.

34 S. Sugihara, A. Blanazs, S. P. Armes, A. J. Ryan and A. L. Lewis, J. Am. Chem. Soc., 2011, 133, 15707-15713.

35 A. Blanazs, R. Verber, O. O. Mykhaylyk, A. J. Ryan, J. Z. Heath, C. W. I. Douglas and S. P. Armes, J. Am. Chem. Soc., 2012, 134, 9741-9748.

36 R. Verber, A. Blanazs and S. P. Armes, Soft Matter, 2012, 8, 9915-9922.
37 L. P. D. Ratcliffe, A. J. Ryan and S. P. Armes, Macromolecules, 2013, 46, 769-777.

38 V. J. Cunningham, L. P. D. Ratcliffe, A. Blanazs, N. J. Warren, A. J. Smith, O. O. Mykhaylyk and S. P. Armes, Polym. Chem., 2014, 5, 6307-6317.

39 I. W. Canton, N. J. Warren, A. Chahal, K. Amps, A. Wood, R. Weightman, E. Wang, H. Moore and S. P. Armes, ACS Cent. Sci., 2016, 2, 65-74.

40 D. E. L. Mitchell, J. R. Lovett, S. P. Armes and M. I. Gibson, Angew. Chem., Int. Ed., 2016, 55, 2801-2804.

41 M. Semsarilar, V. Ladmiral, A. Blanazs and S. P. Armes, Langmuir, 2012, 28, 914-922.

42 M. Semsarilar, V. Ladmiral, A. Blanazs and S. P. Armes, Langmuir, 2013, 29, 7416-7424.

43 E.-R. Kenawy, S. D. Worley and R. Broughton, Biomacromolecules, 2007, 8, 1359-1384.

44 H. Murata, R. R. Koepsel, K. Matyjaszewski and A. J. Russell, Biomaterials, 2007, 28, 4870-4879.

45 M. Malmsten, Soft Matter, 2011, 7, 8725-8736.

46 W. Yuan, J. Wei, H. Lu, L. Fan and J. Du, Chem. Commun., 2012, 48, 6857-6859.

47 J. R. Lovett, N. J. Warren, L. P. D. Ratcliffe, M. K. Kocik and S. P. Armes, Angew. Chem., Int. Ed., 2015, 54, 1279-1283.

48 N. J. Warren and S. P. Armes, J. Am. Chem. Soc., 2014, 136, 10174-10185.

49 V. Sambhy, B. R. Peterson and A. Sen, Angew. Chem., Int. Ed., 2008, 47, 1250-1254.

50 A. Munoz-Bonilla and M. Fernandez-Garcia, Prog. Polym. Sci., 2012, 37, 281-339.

51 E. F. Palermo and K. Kuroda, Appl. Microbiol. Biotechnol., 2010, 87, 1605-1615.

52 S. Lenoir, C. Pagnoulle, C. Detrembleur, M. Galleni and R. Jerome, J. Polym. Sci., Part A: Polym. Chem., 2006, 44, 1214-1224.

53 J. Hoque, P. Akkapeddi, V. Yarlagadda, D. S. S. M. Uppu, P. Kumar and J. Haldar, Langmuir, 2012, 28, 12225-12234.

54 A. Colomer, A. Pinazo, M. A. Manresa, M. P. Vinardell, M. Mitjans, M. R. Infante and L. Perez, J. Med. Chem., 2011, 54, 989-1002.

55 J. Madsen, S. P. Armes, K. Bertal, S. MacNeil and A. L. Lewis, Biomacromolecules, 2009, 10, 1875-1887. 